Original Research Article

\title{
A prospective study of drug utilization in patients attending ophthalmology outpatient department at KBN teaching and general hospital of Gulbarga, India
}

\author{
Md Mohsin Ahmed ${ }^{1}$, Amogh Harsoor ${ }^{2 *}$, Sana Nizami²
}

${ }^{1}$ Department of Pharmacology, ${ }^{2}$ Department of Ophthalmology, KBN Institute of Medical Sciences, Gulbarga, Karnataka, India

Received: 11 July 2018 Accepted: 16 July 2018

*Correspondence to: Dr. Amogh Harsoor, Email: amogh.harsur@ gmail.com

Copyright: () the author(s), publisher and licensee Medip Academy. This is an openaccess article distributed under the terms of the Creative Commons Attribution NonCommercial License, which permits unrestricted noncommercial use, distribution, and reproduction in any medium, provided the original work is properly cited.

\begin{abstract}
Background: Drug utilization studies are an important part of rational use of drugs. Assessment of drug use pattern especially in developing countries is becoming increasingly necessary to promote the rational use of drugs. This study was planned to prospectively assess the drug utilization pattern in Ophthalmology outpatient department at KBN teaching and General hospital.
\end{abstract}

Methods: After approval from Ethics Committee, the prescriptions of 1000 outpatients were analyzed using a predesigned form to record information from the OPD prescriptions. Mentioned WHO drug use indicators and additional indices were analyzed: Average number of drugs per prescription, number of encounters with antibiotics, percentage of encounters with injections, percentage of drugs prescribed by their generic names, percentage of drugs prescribed from the National Essential Drug List (NEDL), etc.

Results: Prescription analysis showed that the average number of drugs per prescription was 2.6. The drugs were prescribed in the several forms, predominant dosage form been topical eye drops $(69.58 \%)$ followed by tablets $(11.98 \%)$, ointments $(10.17 \%)$ and capsules $(6.6 \%)$. The 'dosage form' was indicated for all of the drugs prescribed, the 'frequency' of drug administration was present in $96.5 \%$ of the drugs, and the duration of treatment for $82 \%$ of the drugs prescribed. Topical Antimicrobial agents were the most commonly prescribed drugs. followed by anti-inflammatory and anti-allergic, lubricants, anti-glaucoma drugs, etc. Percentage of drugs prescribed by generic name and from NEDL was $7.98 \%$ and $55 \%$ respectively.

Conclusions: The prescription writing errors were less, however, there was very low generic prescribing and inadequate information about the duration of therapy in many prescriptions. Generic prescribing can be improved. Duration of therapy should be mentioned in all prescriptions. It is essential that appropriate guidelines on the use of topical antimicrobials are required to ensure rational prescribing.

Keywords: Drug utilization evaluation, Ophthalmology, Prospective study, Rational drug use

\section{INTRODUCTION}

In health care system, use of medicines is considered one of the most cost-effective medical interventions for treatment and prevention of disease and it is important to realize that inefficient use of medicines might affect the safety and quality of therapeutic care and wastes resources.

The drug utilization studies is defined as "the marketing, distribution, prescription, and use of drugs in a society, with special emphasis on the resulting medical, social, and 
economic consequences" (WHO). ${ }^{1}$ In the past few decades, marketing of new drugs, variations in the pattern of drug prescribing, concerns about the delayed adverse effects of drugs and the increase in the cost of drugs has increased the importance of drug utilization studies. ${ }^{2}$ Drug utilization studies are powerful exploratory tools to ascertain the role of drugs in the society. ${ }^{3}$

Drug utilization research will often point to and profile the discrepancy that persists between true need and therapeutic practice, and perhaps serve as a tool in correcting it. ${ }^{4}$

Topical ophthalmic Non-Steroidal Anti-Inflammatory Drugs (NSAIDs) can not only produce local irritant effects of conjunctival hyperaemia, burning, stinging and corneal anesthesia but also have association with serious complication like indolent corneal ulceration and full thickness corneal melts. ${ }^{5}$ Antibiotics are widely prescribed for various ophthalmic diseases. The repeated use of ophthalmic antibiotics leads to resistant strains. ${ }^{6}$ Drugs themselves are not as bad as the way in which we use them; a therapeutic audit is required at all levels of the therapeutic chain to ensure safe and effective medical care. ${ }^{7}$ Therefore, the present study was undertaken with the aim to investigate drug utilization and prescribing practices of ophthalmologists in $\mathrm{KBN}$ teaching and General Hospital.

\section{METHODS}

This study was carried out in Outpatient Ophthalmology Department of KBN teaching and General Hospital from January 2016 to December 2016. Permission was obtained from the Institutional Ethics Committee. This was an open label, cross sectional, prospective, non-interventional, observational study conducted by Department of Pharmacology in association with Department of Ophthalmology, KBN Institute of Medical Sciences.

\section{Inclusion criteria}

Newly registered adult patients of either sex who visited the Ophthalmology Outpatient Department with complaints of red eye, discharge from eyes, itching, redness, foreign body sensation, swelling, raised intraocular pressure, and eye trauma were included.

\section{Exclusion criteria}

Cases of cataract, postoperative follow ups, any diagnostic test/procedure, and repeated follow-up cases were excluded from the study.

Data was collected prospectively from the out-patients unit of the ophthalmology Department between 9 AM and 12 PM, twice a week (Monday and Tuesday) for a period of 12 months. Prescriptions from each patient are taken into consideration for this study and only those medications used for treating ocular disorders were considered.
All drugs prescribed were noted including dose, route, dosage form, frequency of administration, indications for prescription and duration of therapy, numbers of drugs prescribed from Essential Drug list were also noted as per WHO/International Network of Rational Use of Drugs (INRUD) drug use indicators. ${ }^{8}$

Essential medicines as defined by the WHO are those drugs that satisfy the health-care needs of the majority of the population; they should therefore be available at all times in adequate amounts and in appropriate dosage forms, at a price the community can afford. ${ }^{9}$ Central Drugs Standard Control Organization, the regulatory body in India, has recently formulated the National list of essential medicines in 2015.

A total of 1000 prescriptions were analyzed following WHO recommendation. ${ }^{8}$

Data was coded and entered with the help of a statistician to minimize the data entry errors. Data analyzed on EPI INFO version 3.5.4 and MS EXCEL. The different variables were expressed as frequencies and percentages.

\section{RESULTS}

A total of 1000 prescriptions were analyzed. The total number of drugs in these prescriptions was 2604. The number of drugs per prescription varied from one to five, with an average of 2.6 per prescription.

Majority prescriptions $46.5 \% \quad(n=465)$ had two drugs, followed by three drug prescription in $20.5 \% \quad(n=205)$, single drug prescription in $19.6 \%(n=196)$, four drug were prescribed in $11.7 \% \quad(n=117)$ and five drugs were prescribed in $1.7 \%(\mathrm{n}=17)$ as seen in Table 1 .

Table 1: Number of drugs prescribed per prescription.

\begin{tabular}{|ll|}
\hline Number of drugs & $\begin{array}{l}\text { Number of individual } \\
\text { prescription }(\%)\end{array}$ \\
\hline 1 & $196(19.6 \%)$ \\
\hline 2 & $465(46.5 \%)$ \\
\hline 3 & $205(20.5 \%)$ \\
\hline 4 & $117(11.7 \%)$ \\
\hline 5 & $17(1.7 \%)$ \\
\hline Total & $1000(\sim 100 \%)$ \\
\hline
\end{tabular}

Table 2: The dosage form of various drugs.

\begin{tabular}{|ll|}
\hline Dosage form & Number of drugs \\
\hline Topical eye drops & $1818(69.58 \%)$ \\
\hline Tablets & $312(11.98 \%)$ \\
\hline Ointment & $265(10.17 \%)$ \\
\hline Capsule & $172(6.6 \%)$ \\
\hline Injection & $37(1.4 \%)$ \\
\hline Total & $2604(\sim 100 \%)$ \\
\hline
\end{tabular}


Drugs were prescribed in five different dosage forms. Eye drops were the most commonly used dosage form $(69.58 \%)$ followed by tablets $(11.98 \%)$, ointments $(10.17 \%)$ capsules $(6.6 \%)$ and injections contributed to $1.4 \%$ of all the dosage forms prescribed as seen in Table 2.

Study also revealed that $208 \quad(7.98 \%)$ drugs were prescribed by generic name and $2396(92.01 \%)$ drugs were prescribed by brand name as seen from Figure 1.

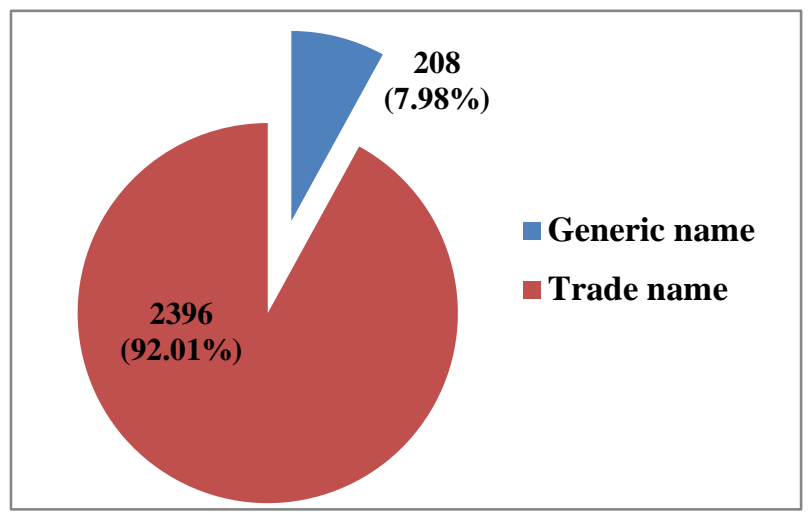

Figure 1: Drugs prescribed by generic and brand names.

The percentage of drugs prescribed from essential drug list was 55\% (1432/2604) from National List of Essential Medicines, 2015. Dosage forms of the drugs were mentioned for 2498/2604 (95.93\%) of the drugs. Frequency of drug administration was mentioned for $2513 / 2604(96.5 \%)$ of the drugs. Duration of treatment was specified for $2135 / 2604(82 \%)$ of the prescribed drugs. Drugs as fixed-dose combinations were seen in 573 (22\%) and the patient's knowledge of correct dosage for prescribed drug was $96 \%$ as mentioned in Table 3.

Table 3: Drug utilization based indicators.

\begin{tabular}{|ll|}
\hline WHO Indicators assessed & $\begin{array}{l}\text { Data } \\
\text { values }\end{array}$ \\
\hline Average number of drugs per prescription & 2.6 \\
\hline $\begin{array}{l}\text { Percentage of drugs prescribed by generic } \\
\text { names }\end{array}$ & 18 \\
\hline Percentage of prescriptions with antibiotics & 55 \\
\hline Percentage of drugs prescribed from NLEM & $55 \%$ \\
\hline Dosage forms recorded & $95.93 \%$ \\
\hline Frequency of therapy recorded & $96.5 \%$ \\
\hline Duration of therapy recorded & $82 \%$ \\
\hline Drugs as fixed-dose combination & $22 \%$ \\
\hline Patient's knowledge of the correct dosage & $96 \%$ \\
\hline * NLEM: National List of Essential Medicines & \\
\hline
\end{tabular}

The number of prescriptions with antibiotics were $782 / 1000(78.2 \%)$ which accounted for 1536/2604 (59\%) of the total number of drugs prescribed, this was followed by anti-inflammatory and anti-allergic 338 (13\%), lubricants 234 (9\%), Anti glaucoma 156 (6\%), 'Mydriatics and cycloplegics' 208 (8\%), Miotics 78 (3\%) and multivitamins $52(2 \%)$ as seen in Table 4.

Table 4: The various classes of drugs used.

\begin{tabular}{|lll|}
\hline Class of drugs & $\begin{array}{l}\text { Number } \\
\text { of drugs }\end{array}$ & Percentage $(\%)$ \\
\hline Antibiotics & 1536 & 59 \\
\hline $\begin{array}{l}\text { Anti-inflammatory } \\
\text { and anti allergic }\end{array}$ & 338 & 13 \\
\hline Lubricant & 234 & 9 \\
\hline Anti glaucoma & 156 & 6 \\
\hline $\begin{array}{l}\text { Mydriatics and } \\
\text { cycloplegics }\end{array}$ & 208 & 8 \\
\hline Miotics & 78 & 3 \\
\hline Multivitamins & 52 & 2 \\
\hline Total & $\mathrm{N}=2604$ & 100 \\
\hline
\end{tabular}

Of the total 1536 antibacterial drugs prescribed, Fluoroquinolones were the most common group of antibiotics $937 / 1536(61 \%)$ followed by penicillins 184/1536 (12\%), Chloramphenicol 169/1536 (11\%), Tetracyclines 107/1536 (7\%), polypeptides 93/1536 (6\%) and Aminoglycosides 46/1536 (3\%) as seen in Table 5.

Table 5: Prescribing frequency of antibacterial classes.

\begin{tabular}{|lll|}
\hline Antibacterial class & $\begin{array}{l}\text { Number } \\
\text { of drugs }\end{array}$ & $\begin{array}{l}\text { Percentage } \\
(\%)\end{array}$ \\
\hline Fluoroquinolones & 937 & 61 \\
\hline Penicillins & 184 & 12 \\
\hline Chloramphenicol & 169 & 11 \\
\hline Tetracyclines & 107 & 7 \\
\hline Polypeptides and others & 93 & 6 \\
\hline Aminoglycosides & 46 & 3 \\
\hline Total & $\mathrm{N}=1536$ & 100 \\
\hline
\end{tabular}

\section{DISCUSSION}

The indicators of prescribing practices measure the performance of health care providers in several key dimensions related to the appropriate use of drugs. ${ }^{8}$

WHO drug use indicators were used in the present studies.

Of the 1000 prescriptions containing 2604 drugs, number of drugs per prescription ranged from one to five. In this study, most commonly two drugs were noted per prescription. Average number of drugs per prescription is an important index as it tends to measure the degree of polypharmacy. ${ }^{10}$

It is preferable to keep the number of drugs per prescription as low as possible since higher Figurers lead to increased risk of drug interactions, adverse effects, 
development of bacterial resistance and increased cost to the patient. ${ }^{11}$

In this study, most of the drugs were prescribed topically, $69.58 \%$ in form of drops and $10.17 \%$ in the form of topical eye ointment. Administering the drugs topically for eye diseases minimized their systemic adverse effects.

Generic drug use in India is yet to gain widespread popularity; the economic benefits of generic drug use are however well-known and undisputed. ${ }^{12}$ Recently, regulatory authorities of different countries are advocating generic prescribing to cut total health-care cost.

In this regard, the percentage of drugs prescribed by generic names in this study was $7.98 \%$, inadequate sensitization of the clinicians to generic prescribing and the frequent visit of the medical representatives in health facilities may be the probable cause of the under prescribing of the drugs by generic name.

The percentage of drugs prescribed from the National List of Essential Medicines 2015 was 55\% which is higher compared to studies conducted in India. ${ }^{13}$ The dosage form and the frequency of drug administration have been recorded in $95.93 \%$ and $96.5 \%$ of the cases respectively.

In $82 \%$ of the prescriptions, the duration of therapy was noted. This study showed a need for improvement in prescription writing, as the duration of therapy was missing in $18 \%$ of the prescriptions.

In this study, percentage of prescriptions with antibiotics was around $55 \%(n=550 / 1000)$. And thereby antibacterial antibiotics constituted 59\% (1536/2604) of the total drugs prescribed. Some of these antibiotics were prescribed along with steroids, while most prescriptions had no such combinations with steroid as a fixed dose combination. Other similar studies in ophthalmology in India have reported $30 \%-45 \%$ encounters with antibiotics which is lower than our study. ${ }^{14,15}$

Fluoroquinolones were the most common group of antibiotics prescribed which were similar to reports of previous studies done in ophthalmology. ${ }^{13,14,15}$ Ciprofloxacin $0.3 \%$ as drops and ointment is included in National List of Essential Medicines 2015, deemed to be available at Primary, Secondary and Tertiary levels of health care and hence preferred in many prescriptions as patients could use them free of cost. ${ }^{14}$

Newer fluoroquinolones like Moxifloxacin were prescribed in severe cases. The prescribing pattern observed in the current study was in accordance with the accepted norms of treatment for ocular diseases,

The present study revealed certain lacunae in the prescribing practices of the Ophthalmologists in this institute evident by the low generic prescribing, inadequate information about duration of therapy in many prescriptions. There is margin for betterment. Ophthalmologists should be encouraged to prescribe by generic name and opt for essential drugs from National List of Essential Medicines. The study suggests educational initiative, development of drug policy, and National Essential drug list based hospital formulary to reduce the drug cost and ensure rational use of medicines.

\section{ACKNOWLEDGEMENTS}

Authors would like to thank Janab Late Syed Shah Muhammad Hussaini, The founder President of 'Khaja Education Society' for establishing various institutes for the service to mankind and Janab Dr. Syed Shah Khusro Hussaini, The Hon'ble President of 'Khaja Education Society' for equipping these institutes with 'State of the Art' facilities to cater the needs of several students and researchers.

\section{Funding: No funding sources}

Conflict of interest: None declared

Ethical approval: The study was approved by the Institutional Ethics Committee of KBNIMS, Gulbarga, India vide letter No.: KBNIMS/IEC/2015-16/17 (Dated 13/11/2015)

\section{REFERENCES}

1. Introduction to Drug Utilization Research. Oslo, Norway: World Health Organization; 2003:8.

2. Hasmnis AA, Patil SS, Narayan KA, Rashid AK, Mohanty BK. Drug utilization study for acute illnesses in village anggol, Malaysia; The findings of a household survey. Al Ameen J Med Sci. 2010;3(2):165-8.

3. Jaiprakash H, Vinotini K, Min VC. Drug utilization study of antihypertensive drugs in a clinic in Malaysia. Int J Basic Clin Pharmacol. 2017 Jan 31;2(4):407-10.

4. Dukes MNG. WHO Regional Publications European Series; No. 45. Drug utilization studies: methods and uses. $36 . \quad$ Available at: http://apps.who.int/medicinedocs/documents/s21868e n/s21868en.pdf

5. Gaynes BI, Fiscella R. Topical nonsteroidal antiinflammatory drugs for ophthalmic use: a safety review. Drug Saf. 2002;25(4):233-50.

6. Kim SJ, Toma HS. Antimicrobial Resistance and Ophthalmic Antibiotics1-Year Results of a Longitudinal Controlled Study of Patients Undergoing Intravitreal Injections. Arch Ophthalmol. 2011;129(9):1180-8.

7. Krishnaswamy K, Kumar DB, Radhaiah G. A drug survey- precepts and practices. Eur J Clin Pharmacol 1985;29(3):363-70.

8. World Health Organization (WHO) and International Network for Rational Use of Drugs, How to Investigate Drug Use in Health Facilities: Selected Drug Use indicators, WHO/DAP/93.1, WHO, Geneva, Switzerland; 1993. 
9. The Selection and Use of Essential Medicines WHO Technical Report Series, No. 914; 2003. Available at: http://www.apps.who.int/medicinedocs/en/d/Js4875e/ 5.2.html

10. Jadhav PR, Moghe VV, Deshmukh YA. Drug utilization study in ophthalmology outpatients at a tertiary care teaching hospital. ISRN pharmacology. 2013 Dec 22;2013.

11. Sharma D, Reeta KH, Badyal DK, Garg SK, Bhargava VK. Antimicrobial prescribing pattern in an Indian tertiary hospital. Ind J Physiol Pharmacol. 1998 Oct;42(4):533-7.

12. Das M, Choudhury S, Maity S, Hazra A, Pradhan T, Pal A, Roy RK. Generic versus branded medicines: An observational study among patients with chronic diseases attending a public hospital outpatient department. J Nat Sc Biol Med. 2017; 8(1):26-31.

13. National List of Essential Medicines (NLEM); 2015:60. http://apps.who.int/medicinedocs/documents/s23088e n/s23088en.pdf

14. Maniyar Y, Bhaxivitamath P, Akkone V. A Drug Utilization Study In The Ophthalmology Department of a Medical College, Karnataka, India J Cli Diagnos Resear. 2011;5(1):82-4.

15. Vaniya HV, Darji NH, Patel VR, Gohel DJ. Drug Utilization Study in Ophthalmology Outpatients in a Tertiary Care Hospital. Advances in Pharmacology and Pharmacy. 2016 Jun;4(2):11-5.

Cite this article as: Ahmed MM, Harsoor A, Nizami S. A prospective study of drug utilization in patients attending ophthalmology outpatient department at KBN teaching and general hospital of Gulbarga, India. Int J Basic Clin Pharmacol 2018;7:1512-6. 